\title{
RECIST zum Download
}

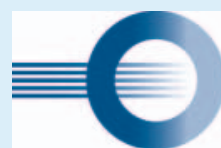

AC Onkologische Bildgebung

in der Deutschen Röntgengesellschaft
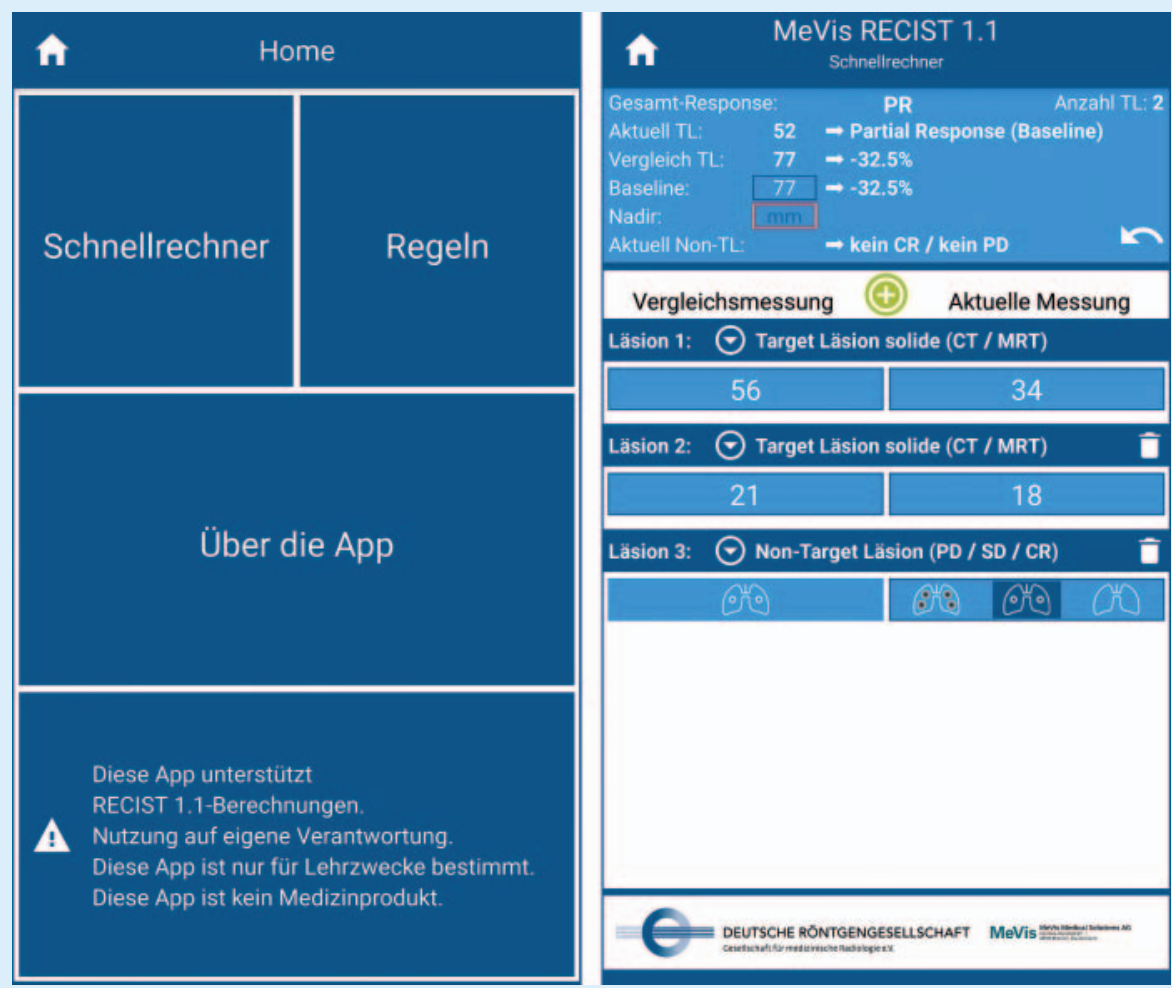

Die neue RECIST-App steht ab Frühjahr dieses Jahres zur Verfügung.
Die AG Onkologische Bildgebung hat in Zusammenarbeit mit der MeVis Medical Solutions AG (Bremen) eine RECIST-App entwickelt.

Unter Leitung von PD Dr. Thorsten Persigehl wurde eine App programmiert, die eine einfache Berechnung der Tumorgrößenveränderung und die automatische Kalkulation des Therapieansprechens gemäß der RECIST 1.1 Kriterien ermöglicht. Die deutschsprachige RECIST-App steht als kostenloser Download im Google Play Store und iTunes Store zur Verfügung (MeVis RECIST 1.1). Hiervon erhofft sich die AG eine zunehmende Anwendung der strukturierten Befundung und der objektiven Response Evaluation in der klinischen Routine.

\section{MEHR INFORMATIONEN:}

www.onkologische-bildgebung.drg.de 